\title{
Influence of Ambient Temperature on Frequency and Intensity of Menopausal Hot Flashes $^{a}$
}

\author{
F. KRONENBERG ${ }^{b}$ AND R. M. BARNARD ${ }^{b, c}$ \\ ${ }^{b}$ Department of Rehabilitation Medicine \\ College of Physicians \& Surgeons \\ Columbia University \\ New York, New York 10032 \\ 'School of Nursing \\ University of Michigan \\ Ann Arbor, Michigan 48109
}

Hot flashes (HFs) are one of the most distressing problems experienced by women during their menopausal years. HFs are short, transient periods of intense feelings of heat, flushing, and sweating, often accompanied by palpitations and anxious feelings. Although the mechanism is not known, it has been hypothesized that a HF is triggered by a sudden downward resetting of a central thermoregulatory "setpoint" in the hypothalamus. ${ }^{4}$ Many menopausal women report their HFs are worse in the summer than in the winter. Thus far, published reports of relationships of ambient temperature $\left(T_{a}\right)$ with the frequency of menopausal HFs have been limited to a few studies which compared day-to-day variations in HF frequency with the variations in atmospheric temperature (daily minimum/maximum or daily mean). Two studies reported a positive relationship between air temperature and daily HF frequency, ${ }^{1,3}$ while two others found no relationship. ${ }^{2,5}$ HFs have not been studied in which $T_{a}$ was systematically varied. The purpose of this study is to examine subjectively and objectively the frequency and intensity of menopausal HFs at cool $\left(19^{\circ} \mathrm{C}\right)$ and warm $\left(31^{\circ} \mathrm{C}\right) \mathrm{T}_{\mathrm{a}} \mathrm{s}$.

Women experiencing frequent $(10+$ per day) HFs were recruited as participants through local newspaper advertisements. Individuals with reported medical or psychiatric disorders or with current or recent hormone therapy were excluded. Written informed consent was obtained.

Heart rate, skin resistance, and skin, core, and ambient temperatures were measured at 30-second intervals with a Squirrel Physiological Meter/Logger (Science Electronics, Dayton, Ohio), a 12-channel, 8-bit portable data logger with a real-time clock and $128 \mathrm{~K}$ memory. Heart rate was measured using standard EKG electrodes. Skin temperatures were measured at several locations (finger, chest, shoulder) using thermistors (YSI, Series 400) attached to the skin with tape and collodion. Internal (core) temperature was measured by a disposable thermistor (YSI 491A) taped to a tampon and inserted vaginally. Ambient temperature was measured using a thermistor (YSI Series 400) in the air within a meter of the subject's head. Skin resistance was measured using silver silver-chloride electrodes, placed approximately $4 \mathrm{~cm}$ apart on the chest over the upper sternum. Data were collected over an 8-hour period with the subject seated in a comfortable

a This work was partially supported by the Vidda Foundation, the Florence and Herbert Irving Endowment, and Grants NIH 1F33NR06351 and BRSG S07RR-05796. 
chair in a temperature-controlled $\left( \pm 1.0^{\circ} \mathrm{C}\right)$ environmental room $\left(15^{\prime} \times 25^{\prime}\right)$. Presentation of $\mathrm{T}_{\mathrm{a}}$ was randomized. After an initial 30-minute equilibration, recording was started. Subjects recorded the time and peak intensity (on scale of 1-10) of each HF, eating, and all other activities during the day on a HF Log Sheet. They spent most of their time reading. Meals and beverages were served in the room. Subjects left the room only to use the bathroom.

Every self-reported HF was associated with corresponding changes in physiological parameters. HF frequency and mean peak intensity were calculated for each subject at each $\mathrm{T}_{\mathrm{a}}$. A paired $t$ test was used to compare differences in HF frequency between the two $\mathrm{T}_{\mathrm{a}} \mathrm{s}$. Peak HF intensity was compared similarly. Eighthour core temperatures for the six experiments were compared using analysis of variance, followed by a post hoc comparison which contrasted the three core temperatures at the warm $\mathrm{T}_{\mathrm{a}}$ with the three temperatures at the cool $\mathrm{T}_{\mathrm{a}}$. A similar analysis was performed on the 8-hour heart rate data.

There were significantly fewer hot flashes $(t=7.8, p=0.016)$ and lower intensity of these hot flashes $(t=5.8, p=0.000)$ in the cool $\mathrm{T}_{\mathrm{a}}$ than in the warm $\mathrm{T}_{\mathrm{a}}$ (TABLE 1 and Figs. 1 and 2). Mean core temperature $(\mathrm{F}=6135.382, p=0.000)$ and mean heart rate $(F=4553.468, p=0.000)$ were significantly lower at cool $T_{a}$

TABLE 1. Selected Measures at Warm and Cool Ambient Temperatures

\begin{tabular}{lccc}
\hline \multicolumn{1}{c}{ Measure } & Cool $\mathrm{T}_{\mathrm{a}}$ & Warm $\mathrm{T}_{\mathrm{a}}$ & \\
& Mean $\pm \mathrm{SD}$ & Mean $\pm \mathrm{SD}$ & $p$ \\
\hline Number of hot flashes & $2.7 \pm 1.5$ & $11.7 \pm 2.1$ & $0.016^{a}$ \\
Peak intensity of hot flashes & $2.8 \pm 0.9$ & $5.7 \pm 2.1$ & $0.000^{a}$ \\
${\text { Core temperature }\left({ }^{\circ} \mathrm{C}\right)^{c}}^{\text {Heart rate }(\mathrm{bpm})^{c}}$ & $36.98 \pm 0.17$ & $37.36 \pm 0.27$ & $0.000^{b}$ \\
\hline
\end{tabular}

${ }^{a}$ Paired $t$ test.

${ }^{b}$ Analysis of variance, post hoc comparison test.

${ }^{c}$ Mean of 30-second data sampling during 8-hour studies of three subjects.

than at warm $T_{\mathrm{a}}$. Thermoregulatory and cardiovascular responses were appropriate for the respective thermal environments. At the cool $T_{a}$ there was vasoconstriction of the skin; at the warm $T_{a}$ there was vasodilatation, increased heart rate, and low-grade sweating. Thus, at each $T_{a}$, different variables provided better markers of the HF occurrence: in the warm $T_{a}$, upper body skin temperature (as an index of sweating) and in the cool $T_{a}$, finger temperature and skin resistance (FIG. 2).

As hypothesized, the frequency and intensity of HFs differed between the two $T_{a} s$. The difference in $H F$ intensity ratings between the warm and cool $T_{2} s$ may be related to differences in physiological responses at the two temperatures. The perception of "intensity" probably represents an integrated combination of several inputs, including sweating, increased heart rate, and some internal (thus far intangible) variables.

In conclusion, HF frequency and intensity are greater at warm than cool ambient temperatures. Women experiencing frequent and/or intense hot flashes may reduce their discomfort by "keeping cool." Exploration of the mechanism is continuing. 


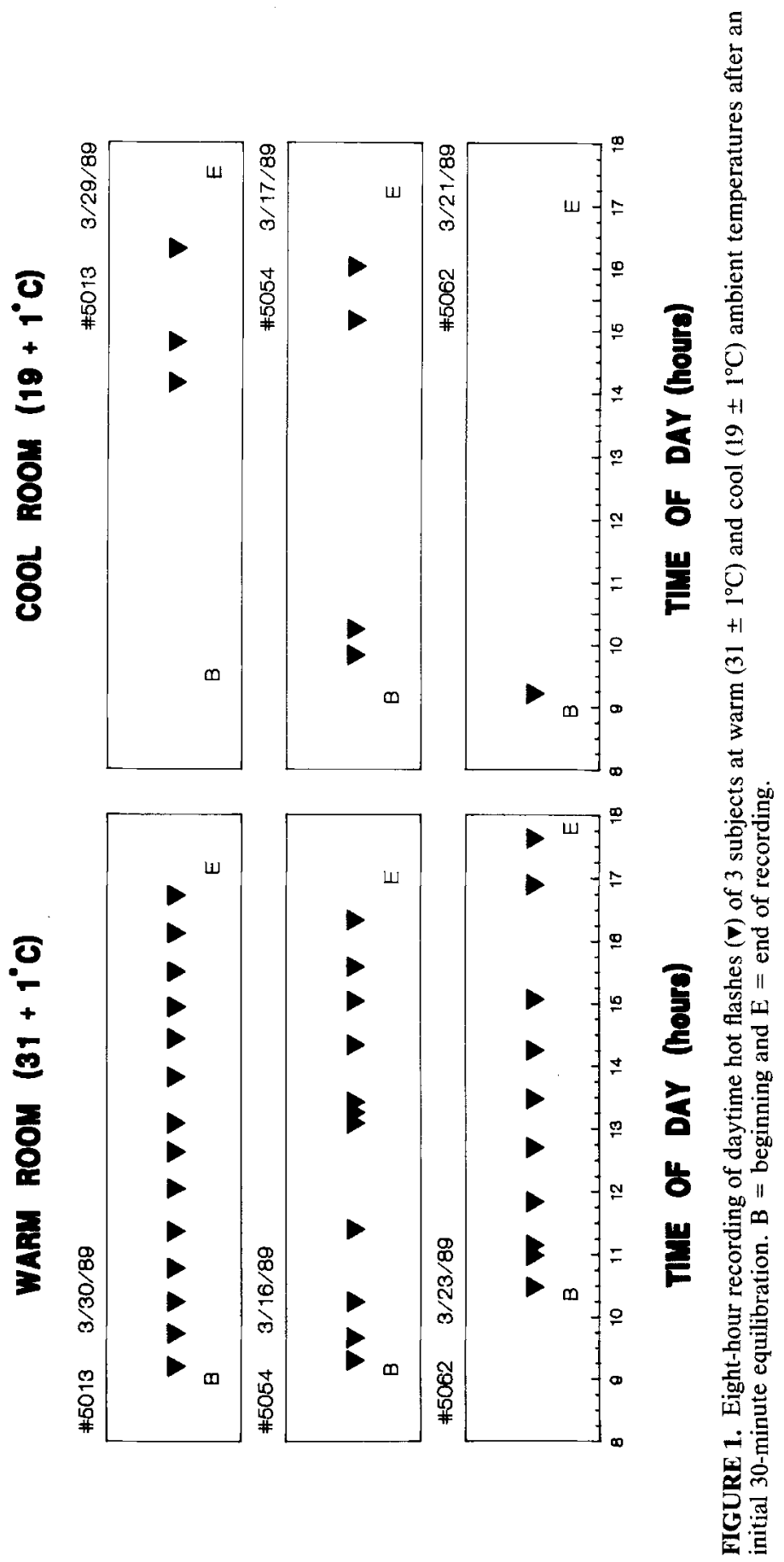




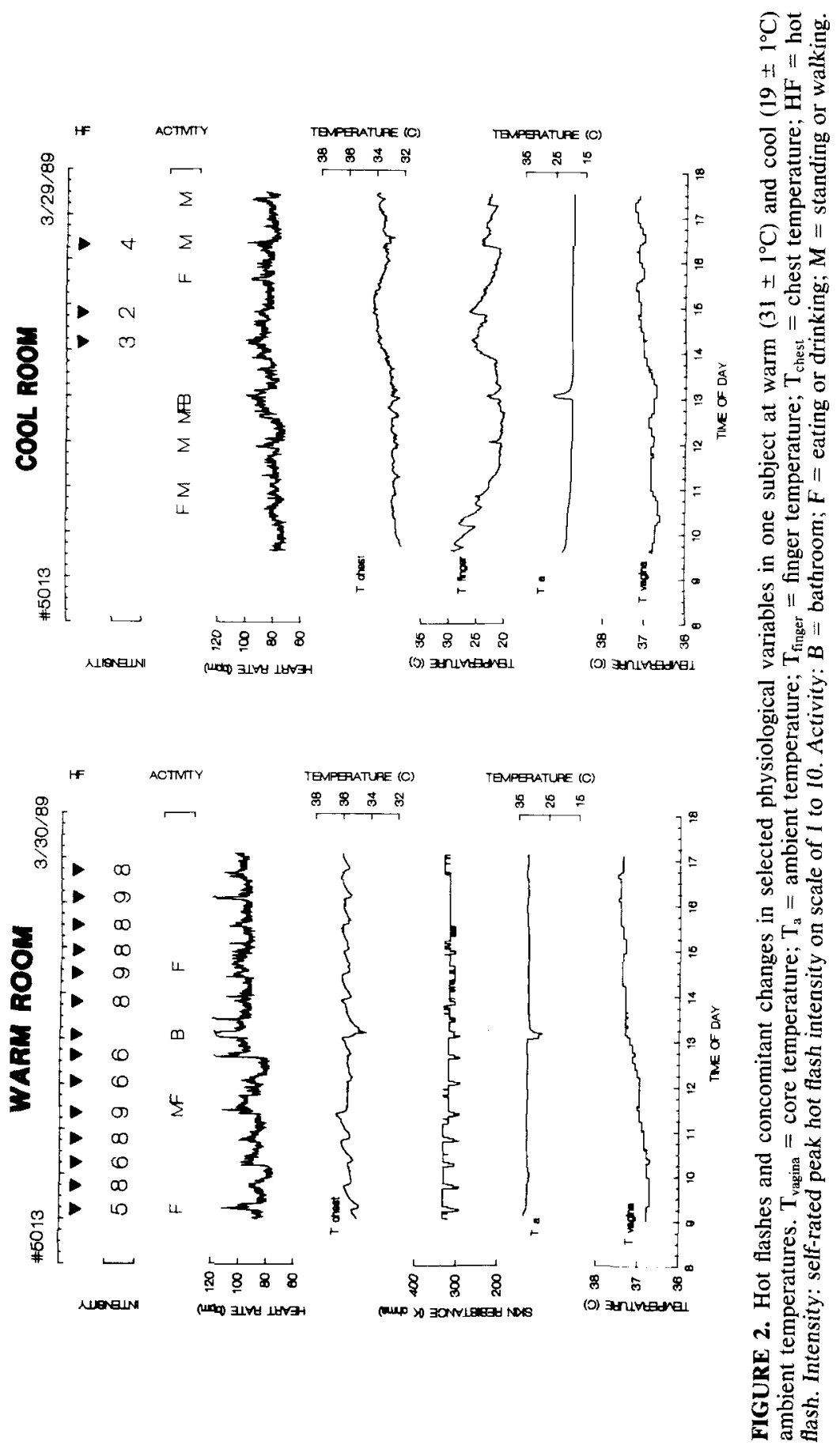




\section{REFERENCES}

1. Coope, J., S. Williams \& J. S. Patterson. 1978. A study of the effectiveness of propranolol in menopausal hot flashes. Br. J. Obstet. Gynaecol. 85: 472-475.

2. Gannon, L., S. HANSEL \& J. Goodwin. 1987. Correlates of menopausal hot flashes. J. Behav. Med. 10: 277-285.

3. Molnar, G. 1981. Menopausal hot flashes: Their cycles and relation to air temperature. Obstet. Gynecol. 57: 525-555.

4. Tataryn, I. V., P. Lomax, J. G. Bajorek, W. Chesarek, D. R. Meldrum \& H. L. JuDD. 1980. Postmenopausal hot flushes: A disorder of thermoregulation. Maturitas 2: $101-107$.

5. VodA, A. 1981. Climacteric hot flash. Maturitas 3: 73-90. 